\title{
LIGHT FLUORESCENCE QUALITY EVALUATION OF OIL DURING MATURITY OF OLIVE
}

\author{
H. E. Hassan ${ }^{1}$, A. A. Abd El-Rahman ${ }^{2}$, M. M. Attia ${ }^{3}$
}

ABSTRACT

The aim of this study was measuring and determination of the optical properties of oil olive during maturity stages (Arbquina variety) using Light Fluorescence Method. The obtained results were as follows: (1) For the lowest value of $\Delta \lambda=20 \mathrm{~nm}$, an effective bandwidth reduction is observed as compared to the emission band, with the synchronous spectrum consisting of a single narrow band with a maximum at $301 \mathrm{~nm}$., (2) At higher $\Delta \lambda$ values at 60 and $80 \mathrm{~nm}$, the maximum of the synchronous spectrum is shifted to the blue and broadened, with additional fluorescence intensity changes. That shifting is related to change of constant wavelength differences ( $\Delta \lambda)$, (3) It is clearly indicated that differentiation of olive oil from high quality oils can be achieved using different wavelength region at interval wavelengths 20 , 40, 60, 80, 100, and $120 \mathrm{~nm}$. (4) The differences of fluorescence intensity during maturity stages for olive oil can be used for classification of oil according to its chemical components, and (5) Qualitative analysis evaluation of some fluorescent components may be of interest for identifying olive oil during olive maturity stages.

\section{INTRODUCTION}

iritsakis et al. (1998) showed that the cultivar of olive had no
significant influence on free acidity, peroxide value and UV
spectrophotometric indices analytical parameters, which are affected by factors causing damage to the fruits (e.g. olive fly attacks or improper systems of harvesting, transport and storage of olives) whereas, some significant differences $(\mathrm{p}<0.001)$ in the values of free acidity and ultraviolet absorbance K232 according to varieties were found.

1- Assoc. Prof., Nat. Inst. of Laser Enhanced Sc. (NILES), Cairo Univ., Egypt

2- Senior Researcher, Ag. Eng. Res. Institute, Ag. Res. Center, El-Dokki, Cairo, Egypt.

3- Postgraduate, Nat. Inst. of Laser Enhanced Sc. (NILES), Cairo Univ., Egypt. 
DeMan (1999) reported that the tocopherols and carotenoids affect the oxidative stability of oils, whereas chlorophylls are responsible for oil photooxidation. Tocopherols $(\alpha, \beta, \gamma$ and $\delta)$ are present in oils in variable amounts, from 70 to $1900 \mathrm{mg} / \mathrm{kg}$, depending on the type of oil. Either pigments of the chlorophyll group occur mainly in crude oils obtained directly by the extraction of oilseed, and are subsequently removed during processing.

Oldham et al. (2000) said that the fluorescence spectroscopy is one of the most promising techniques of increasing importance for complex food analysis. Among the benefits of fluorescence spectroscopy is its enhanced selectivity as compared to other spectroscopic methods, the high sensitivity to a wide array of potential analyses and, in general, the avoidance of consumable reagents and of extensive sample pre-treatment. Owen et al. (2000) mentioned that the olive oil is a fine product with high nutritional value and significant health benefits quality olive oils are expensive owing to the hard and time- consuming tasks involved in the cultivation of olive trees, the harvesting of the fruits, and the extraction of the oil. For this reason, adulteration of higher quality olive oils with either seed oils or olive oils of lower quality is a relatively common fraudulent practice.

Psomiadou and Tsimidou (2001) reported that significant differences between cultivars $(\mathrm{p}<0.001)$ were also observed in pigment contents. The presence of the pigment in the oil depends on several factors, such as the olive cultivar, soil and climatic conditions, fruit ripeness and the processing procedures.

Roca and Minguez-Mosquera (2001a) found that the olive fruit, Olea europaea, a well-known and widespread species of the Oleacea family is a green, fleshy, edible drupe. During the ripening process, it darkens to purple-black at the same time as the oil content increases. As ripening progresses, photosynthetic activity decreases and the concentrations of both chlorophylls and carotenoids decrease progressively. At the end of the maturation process, the violet or purple colour of the olive fruit is due to the formation of anthocyanins.

Gomez-Alonso et al. (2002) showed that phenolic, o-diphenol and atocopherol compounds were the major contributors to the oxidative 
stability, a high correlation values were obtained $(\mathrm{r} 2=0.8,0.8$ and $0.9, \mathrm{p}$ $>0.001)$. Several authors have established a correlation between phenol content and oxidative stability in virgin olive oil

Patre and Mishra (2002) single-wavelength fluorescence measurement is limited in its ability to analyze complicated multi-component samples when they have severely overlapping emission and/or excitation spectra. This can be overcome by using synchronous fluorescence scan (SFS), where overlapping of spectra can be minimized. The selectivity of SFS can still be increased by taking derivative spectrum, applying different multivariate methods, selective fluorescence quenching, threedimensional synchronous measurement or using some of these procedures in combination.

Sikorska et al. (2003) said that the relatively intense band, observed for each of the oils studied, with excitation in the range of about 270-310 $\mathrm{nm}$ and emission in the range of about $300-350 \mathrm{~nm}$, has been ascribed to the emission of tocopherols and tocotrienols. The long-wavelength band, at $350-420 \mathrm{~nm}$ in excitation and $660-700 \mathrm{~nm}$ in emission, present in olive oil (very low intensity), is characteristic of the fluorescence of pigments of the chlorophyll group, which includes chlorophylls $a$ and $b$ and pheophytins $a$ and $b$.

Boskou et al. (2005) mentioned that the continuous interest in the phenolic compounds of virgin olive oil (VOO) has also been extended to all products of the olive tree that can be consumed as common foods (table olives, olive paste) or used as sources for them (raw olives, olive leaves).

Aguilera et al. (2005) said that the $\alpha$-tocopherols in virgin olive oil are important for their nutritional value and for their antioxidant properties, in that they protect the fat components from autoxidation. They constitute the lipophilic antioxidant group and are noted for their effective inhibition of lipid oxidation in all vegetable oils. $\alpha$-Tocopherol, the most important antioxidant, accounts for about $95 \%$ of the total tocopherols in virgin olive oil

Sikorska et al. (2005) mentioned that the total luminescence and synchronous scanning fluorescence spectroscopy techniques were tested as regards their ability to characterize and differentiate edible oils, 
including soybean, sunflower, rapeseed, peanut, olive, grapeseed, linseed and corn oils. Total luminescence spectra of all oils studied as n-hexane solutions exhibit an intense peak, which appears at $290 \mathrm{~nm}$ in excitation and $320 \mathrm{~nm}$ in emission, attributed to tocopherols. Some of the oils exhibit a second long-wavelength peak, appearing at $405 \mathrm{~nm}$ in excitation and $670 \mathrm{~nm}$ in emission, belonging to pigments of the chlorophyll group. Poulli et al. (2005) mentioned that the olive oils show a spectral region around $660 \mathrm{~nm}$, which could be attributed to pigments of chlorophyll groups. Moreover, all studied oils beyond virgin olive oil show a band in the wavelength region higher than $315 \mathrm{~nm}$ when using wavelength interval $20 \mathrm{~nm}$. This band could be attributed to linoleic acid.

Zandomeneghi et al. (2005) reported that the fluorescence characteristics of polyphenols indicate that these compounds absorb around 260- $310 \mathrm{~nm}$ and emit around 310-370 $\mathrm{nm}$ Therefore, the excitation and emission wavelengths chosen for the aim of our study were the same as those used repeatedly in HPLC-fluorimetry. These wavelength settings were considered as a standard operational procedure throughout the method development part.

Konstantina et al. (2007) described the differentiation of virgin olive from olive-pomace, corn, sunflower, soybean, rapeseed and walnut oils using total synchronous fluorescence (TSyF) spectra. TSyF spectra are acquired by varying the excitation wavelength in the region $250-720 \mathrm{~nm}$ and the wavelength interval $(\Delta \lambda)$ in the region from 20 to $120 \mathrm{~nm}$. It is shown that adulterants can be discriminated from virgin olive oil using a wavelength interval of $20 \mathrm{~nm}$ and excitation wavelength region 315-400, 315-392, 315-375, 315-365, 315-375 and 315-360 for olive-pomace, corn, sunflower, soybean, rapeseed and walnut oils, respectively.

The aims of this study are: 1) Measurement of the optical properties of olive oil during maturity stages using light fluorescence, 2) Studying the relationship between emission and absorption intensity according to excitation light, and 4) evaluation of qualitative and quantities of olive oil during maturity. 


\section{MATERIAL AND METHODS}

This study was executed in the Main lab at the National Institute of Laser Enhanced Science (NILES), Cairo University. The experiments and measurements for the optical, color and physical properties of olive were carried out according to the following procedures:

\section{Fruit sample:}

Fruit sample: The study was carried out during season 2009 on olives of the Arbquina variety, from four olive trees, chosen in the plot owned by the Experimental Farm at Agriculture Faculty, Cairo University, Egypt. For each sampling, $5 \mathrm{~kg}$ of olives were picked from the whole perimeter of olive trees selected.

\section{Cold press extraction :}

Oil extraction was performed using a hydraulic piston model T. 20, made in Italy, measuring up to 20 tonns as a cold extraction method in laboratory of NILS, Cairo University, and the olive paste at $28{ }^{\circ} \mathrm{C}$ for 30 min. The oil was filtered and stored at $24{ }^{\circ} \mathrm{C}$ to analysis. A cold press extraction unit was used to extract olive oil. It consists of two units: hydraulic piston ranging between $0-400$ bar and 1- 16 ton and a centrifuge. Approximately $250 \mathrm{~g}$ of fruit was ground to a paste using the hydraulic piston for mixing samples into a mixing jar. The obtained paste was centrifuged at $3500 \mathrm{rpm}$ over $3 \mathrm{~min}$, and then oil filtrated with filter paper, the quantity of oil was transferred to a vial and stored until analysis.

\section{Measurements:}

Analyses were carried out on fruit from the harvests included: chlorophyll content, moisture content, linolic acid, oleic acid, palmatic acid and $\alpha$-tocopherol.

Moisture content was determined by measuring the weight difference when $10 \mathrm{~g}$ of olives were dried in an oven at $105^{\circ} \mathrm{C}$ for $5 \mathrm{~h}$.

Moisture content, $\%=[(\mathrm{M} 1-\mathrm{M} 2) / \mathrm{M} 2] \mathrm{X} 100$

Where : $\mathrm{M} 1$ : is the mass of fruits before drying, $\mathrm{g}$ and

$\mathrm{M} 2$ : is the mass of fruits after drying, $\mathrm{g}$.

Oil content, oil content determination, $50 \mathrm{~g}$ of complete fruit samples were dried in an oven at $80{ }^{\circ} \mathrm{C}$ to constant weight. The dry olives were extracted with hexane using a Soxhlet apparatus. The results were 
expressed as percentage of dry matter (\%DM). the oil content was determined in the following equation:

Oil content, $\%=[(\mathrm{W} 1-\mathrm{W} 2) / \mathrm{W} 2] \mathrm{X} 100$

Where : W1 : is the mass of fruits before drying, $g$ and

$\mathrm{W} 2$ : is the mass of fruits after drying, $\mathrm{g}$.

\section{Absorption measurements:}

Absorption intensity were obtained by measuring the absorption spectra in the range 250-720 nm and varying the wavelength interval in $20 \mathrm{~nm}$ intervals. Measurements were carried out by by T80+ UV/Vis spectrometer. This is a fully computer controlled instrument. Specification of T80+ UV/Vis spectrometer shown in Table 1 and Fig. 1.

\section{Fluorescence measurements:}

TSyF spectra were obtained by measuring the emission spectra in the range $250-720 \mathrm{~nm}$ and varying the wavelength interval from 20 to 180 $\mathrm{nm}$ in $20 \mathrm{~nm}$ intervals. The spectra were fully corrected for the excitation lamp, the photomultiplier detector spectral response and emission excitation gratings.

Measurements were carried out by Perkin Elmer LS55 spectrofluorometer. This is a fully computer controlled instrument using a double-grating monochromator for excitation and a single-grating emission monochromator. Specification of Perkin Elmer LS55 spectrofluorometer shown in Table 2 and Fig. 2.

Excitation and emission slit widths were set at $5 \mathrm{~nm}$. The acquisition interval was maintained at $0.5 \mathrm{~nm}$. Right-angle geometry was used for oil samples diluted in $n$-hexane $(1 \% \mathrm{v} / \mathrm{v})$ in a $10 \mathrm{~mm} \times 10 \mathrm{~mm} \times 45 \mathrm{~mm}$ quartz cell. Synchronous fluorescence (SyF) spectra were collected by simultaneously scanning the excitation and emission monochromator in the $250-750 \mathrm{~nm}$ range.

Total synchronous fluorescence (TSyF) spectra were obtained by measuring the emission spectra in the range $250-750 \mathrm{~nm}$ and varying the wavelength interval from 20 to $120 \mathrm{~nm}$ in $20 \mathrm{~nm}$ intervals.

In this method, both excitation and emission characteristics are included into the spectrum by simultaneous scanning excitation and emission wavelength at a constant difference between them $(\Delta \lambda)$. 
Table 1: T80+ UV/Vis spectrometer

\begin{tabular}{|l|l|}
\hline Item & Specification \\
\hline Model & T80+ UV/Vis spectrometer \\
\hline Manufacture & USA \\
\hline Optical System & Double Beam \\
\hline Wavelength range: & $190 \mathrm{~nm}-900 \mathrm{~nm}$ \\
\hline Photometric Method & $\begin{array}{l}\text { Transmittance, absorbance, reflectance, energy, } \\
\text { concentration. }\end{array}$ \\
\hline Resolution- & $0.1 \mathrm{~nm}$ \\
\hline Absorbance Range: & -9.999 to 9.999 ABS \\
\hline Scanning Speed: & $1000 \mathrm{~nm} /$ min \\
\hline Detector: & Hi sensitivity R928 multiplier detector. \\
\hline Light Source: & $\begin{array}{l}\text { Socket Deuterium Lamp and Socket Tungsten } \\
\text { Halogen Lamp }\end{array}$ \\
\hline Results Printout. & Directly form PC system. \\
\hline
\end{tabular}

Table 2: Specifications of Luminescence Spectrometer (LS 55)

\begin{tabular}{|c|c|}
\hline Item & Specification \\
\hline Model & The Model LS 55 \\
\hline Manufacture & USA \\
\hline Source & $\begin{array}{l}\text { Xenon flash lamp, pulsed at line frequency }(50 \text { or } 60 \mathrm{~Hz}) \text {. } \\
\text { Pulse width at half peak height }<10 \mu \text { s, power equivalent } \\
\text { to } 20 \mathrm{~kW} \text { at continuous operation. }\end{array}$ \\
\hline Optics & $\begin{array}{l}\text { Excitation } 200-800 \mathrm{~nm} \text { with zero order selectable } \\
\text { Emission } 200-650 \mathrm{~nm} \text { with zero order selectable (standard } \\
\text { photomultiplier) } \\
200-900 \mathrm{~nm} \text { with zero order R928 photomultiplier } \\
\text { (optional) }\end{array}$ \\
\hline $\begin{array}{l}\text { Wavelength } \\
\text { accuracy }\end{array}$ & $+1 \mathrm{~nm}$ \\
\hline Scanning speed & $\begin{array}{l}\text { The scanning speed can be selected in increments of } 1 \mathrm{~nm} \\
\text { from } 10-1500 \mathrm{~nm} / \text { minute. }\end{array}$ \\
\hline $\begin{array}{l}\text { Standard sample } \\
\text { holder }\end{array}$ & A single position water holder for $10 \mathrm{~mm}$ cuvettes. \\
\hline Results Printout. & Directly form PC system. \\
\hline
\end{tabular}




\section{PROCESS ENGINEERING}

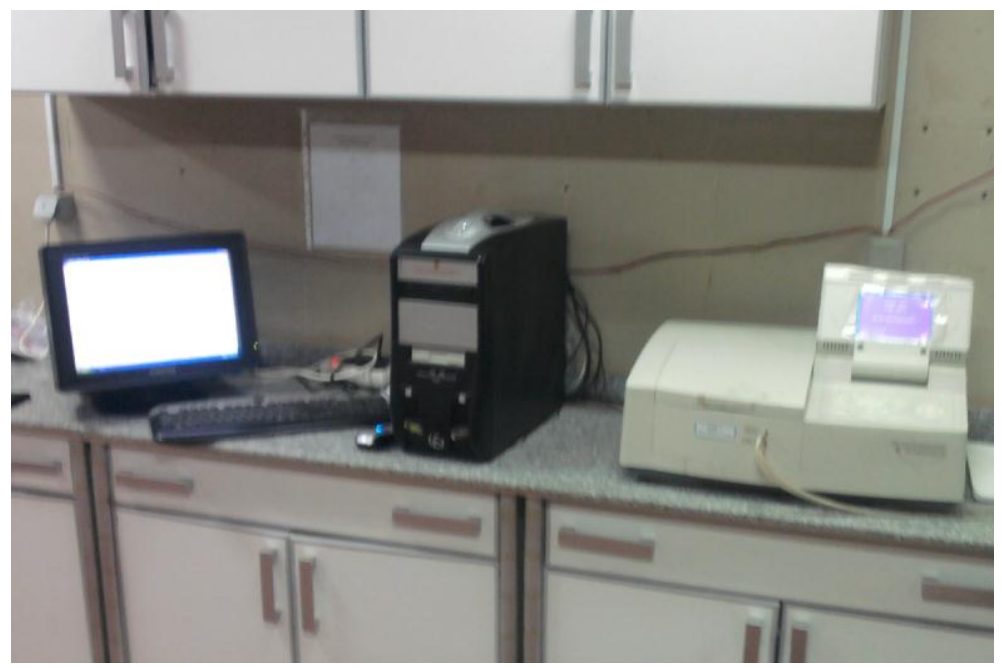

a) Plate of UV/Vis spectrometer .

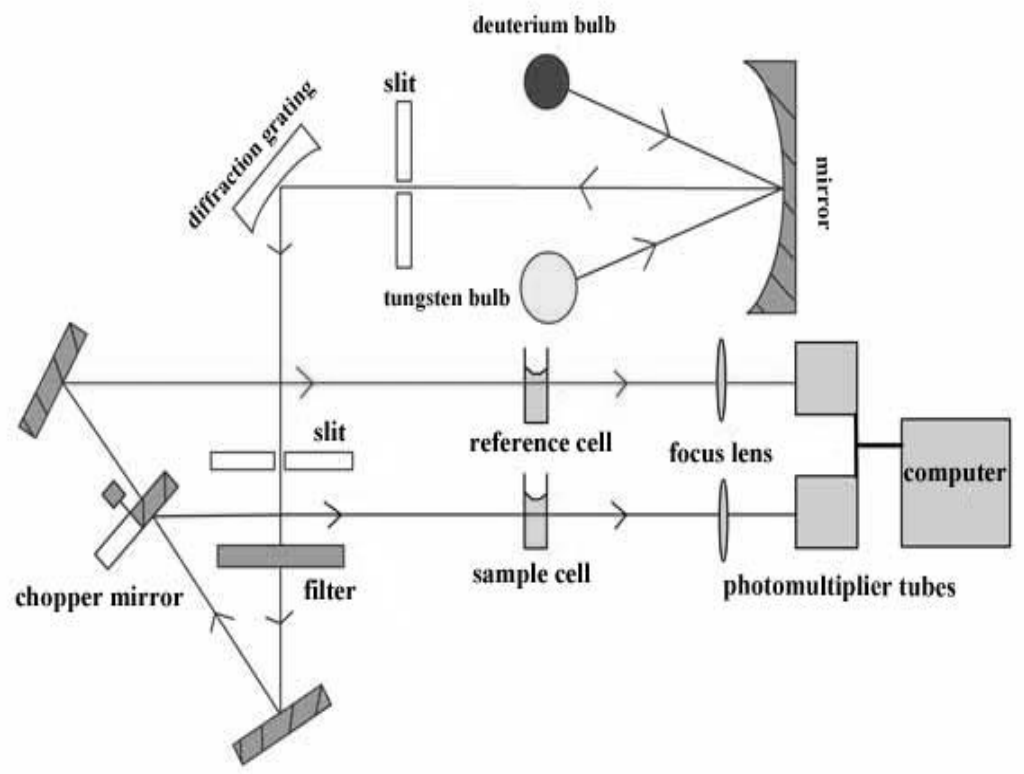

b) Diagram of UV/Vis spectrometer .

Fig. 1 : Diagram of UV/Vis spectrometer (T80+). 


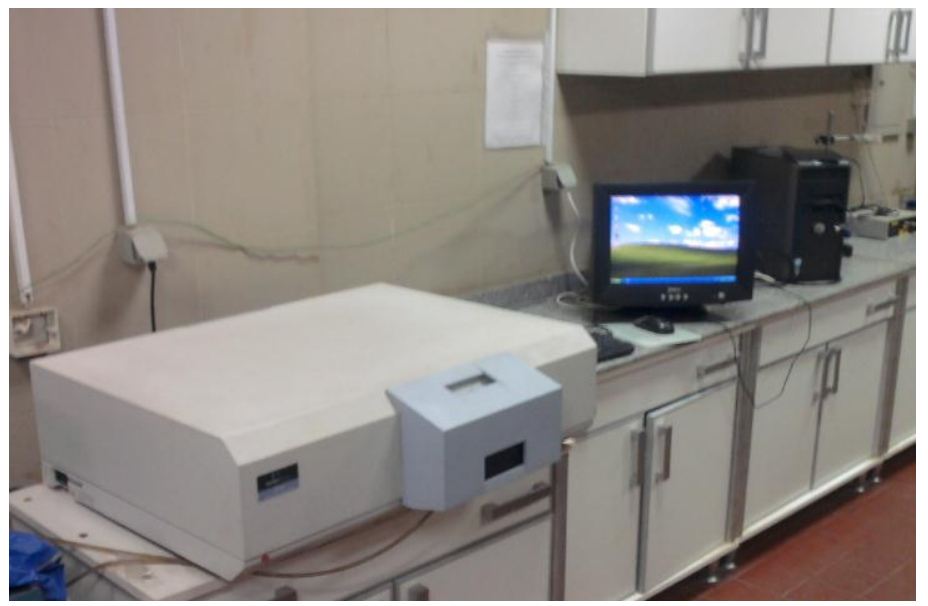

a) Plate of luminescence spectrometer

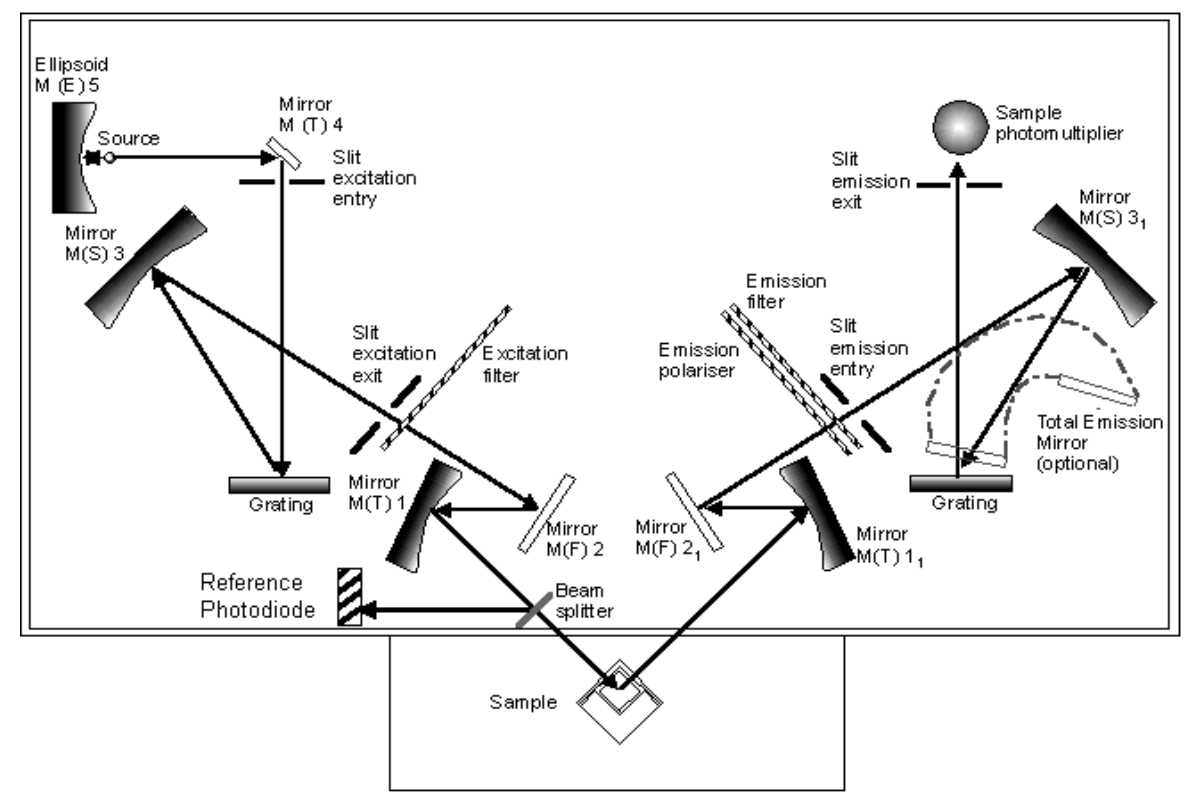

b) Diagram of luminescence spectrometer

Fig. 2: The optical layout of luminescence spectrometer (LS 55) 


\section{RESULTS AND DISCUSSIONS}

\section{Absorption intensity of olive oil:}

Fig. 3: shows the synchronous fluorescence spectra collected by simultaneously scanning the excitation and emission monochromator in the 250-750 $\mathrm{nm}$ range, with constant wavelength differences, $\Delta \lambda$, between them. Six spectra were recorded for each sample, with $\Delta \lambda$ of 20 , 40, 60, 80, 100, $120 \mathrm{~nm}$. Fluorescence intensities were plotted as function of the excitation wavelength. The shape and intensity of synchronous spectra depend on the difference between the excitation and emission wavelengths $\Delta \lambda$, which defines the overlap of the absorption and emission bands.

\section{Fluorescence intensity of olive oil:}

Fig. 3 shows absorption intensity, the value of high intensity is $1.181 \mathrm{a}$. u. at excitation wavelength of $268 \mathrm{~nm}, 0.964$ a. u. at excitation wavelength of $268 \mathrm{~nm}, 1.261 \mathrm{a}$. u. at excitation wavelength of $266 \mathrm{~nm}$, 1.142 a. u. at excitation wavelength of $266 \mathrm{~nm}$, and 0.457 a. u. at excitation wavelength of $282 \mathrm{~nm}$ for olive oil of maturity stages 1, 2, 3, 4 , and 5, respectively.

For the lowest value of $\Delta \lambda=20 \mathrm{~nm}$, an effective bandwidth reduction is observed as compared to the emission band, with the synchronous spectrum consisting of a single narrow band with a maximum at $301 \mathrm{~nm}$. The highest fluorescence intensity is observed for $\Delta \lambda=40 \mathrm{~nm}$ than the others $\Delta \lambda$, which corresponds to the Stokes shift for $\alpha$-tocopherol in $n$ hexane. A further increase of $\Delta \lambda$ results in a lower band intensity. meanwhile, the spectra measured for $\Delta \lambda=60$ and $80 \mathrm{~nm}$ exhibit two bands with relatively low intensities at $665,610 \mathrm{~nm}$ respectively due to successive intensity reduction, which refer to pigment of chlorophylls group then decreased gradually during maturity stages.

At higher $\Delta \lambda$ values at 60 and $80 \mathrm{~nm}$, the maximum of the synchronous spectrum is shifted to the blue and broadened, with additional fluorescence intensity changes. That shifting is related to change of constant wavelength differences $(\Delta \lambda)$.

Also, Fig. 3 shows fluorescence intensity of olive oil of maturity stages at different excitation wavelengths. It was noticed that in the stage 1 , the 
high peaks were $369.41,128.13,135.39,125.98$, and 13.49 a. u., for excitation wavelengths of $299,338,354,376$, and $658 \mathrm{~nm}$, respectively. For the stage 2, the high peaks were 431.72, 124.78, 115.87, 87.80 and 9.70 a.u., for excitation wavelengths of $299,338,354,376$, and $657 \mathrm{~nm}$, respectively. For the stage 3, the high peaks were 291.55, 53.77, 35.70, 115.78 and 12.14 a.u., for excitation wavelengths of 301, 338, 360, 384 and $658 \mathrm{~nm}$, respectively. For the stage 4, the high peaks were 313.33, $131.40,123.22,108.82$ and 3.45 a.u, for excitation wavelengths of 300 , $338,352,375$ and $654 \mathrm{~nm}$, respectively. For the stage 5, the high peaks were $362.11,46.66$ and 42.83 a.u., for excitation wavelengths of 283, 365 and $376 \mathrm{~nm}$, respectively.

Fig. 4: shows the olive oil quality at maturity stages according to fluorescence intensity at different interval wavelengths $20,40,60,80$, $100,120 \mathrm{~nm}$. The peaks of fluoresces intensity at $\Delta \lambda=20 \mathrm{~nm}$ were 13.48 , 9.67, 289.78, 311.81 and 360 a. u. for excitation wave lengths of 658, $660,300,338$ and $282 \mathrm{~nm}$ for stages $1,2,3,4$ and 5, respectively.

The peaks of fluorescence intensity at $\Delta \lambda=40 \mathrm{~nm}$ were $(523.38$ and 218.46 a. u.), (585.9 and 216 a. u.),(406.52 and 226.18 a. u.), (433.52 and 215.75 a. u.) and (465.41 and 77.93 a. u.) for excitation wave lengths of (290 and $356 \mathrm{~nm}),(288$ and $340 \mathrm{~nm}),(294$ and $342 \mathrm{~nm}),(292,342 \mathrm{~nm})$ and (280 and $358 \mathrm{~nm}$ ) for stages $1,2,3,4$ and 5, respectively.

The peaks of fluorescence intensity at $\Delta \lambda=60 \mathrm{~nm}$ were $(411.77,245.65$ and 257.68 a. u.), (463.38, 223 and 6.3 a. u.),( 264.74, 278.69 and $354.36,218.99$ and 8.13 a. u.), (324.93, 375.56 and 220.39 a. u.) and (455.52 and 76.76a. u.) for excitation wave lengths of $(264,322$ and 340 $\mathrm{nm}),(286,322$ and $610 \mathrm{~nm}),(262,266,288,322$ and $610 \mathrm{~nm}),(264,288$ and $322 \mathrm{~nm})$ and (266 and $336 \mathrm{~nm}$ ) for stages 1,2,3,4 and 5, respectively.

The peaks of fluorescence intensity at $\Delta \lambda=80 \mathrm{~nm}$ were (466.23 a. u.), (410.99 a. u.),(308.34 a. u.), (364.47, 238.67 and 190.23 a. u.) and (505 a. u.) for excitation wave lengths of $(258 \mathrm{~nm}),(258 \mathrm{~nm}),(258 \mathrm{~nm}),(258$, 286 and 320nm) and (258 nm) for stages 1, 2,3,4 and 5, respectively. 

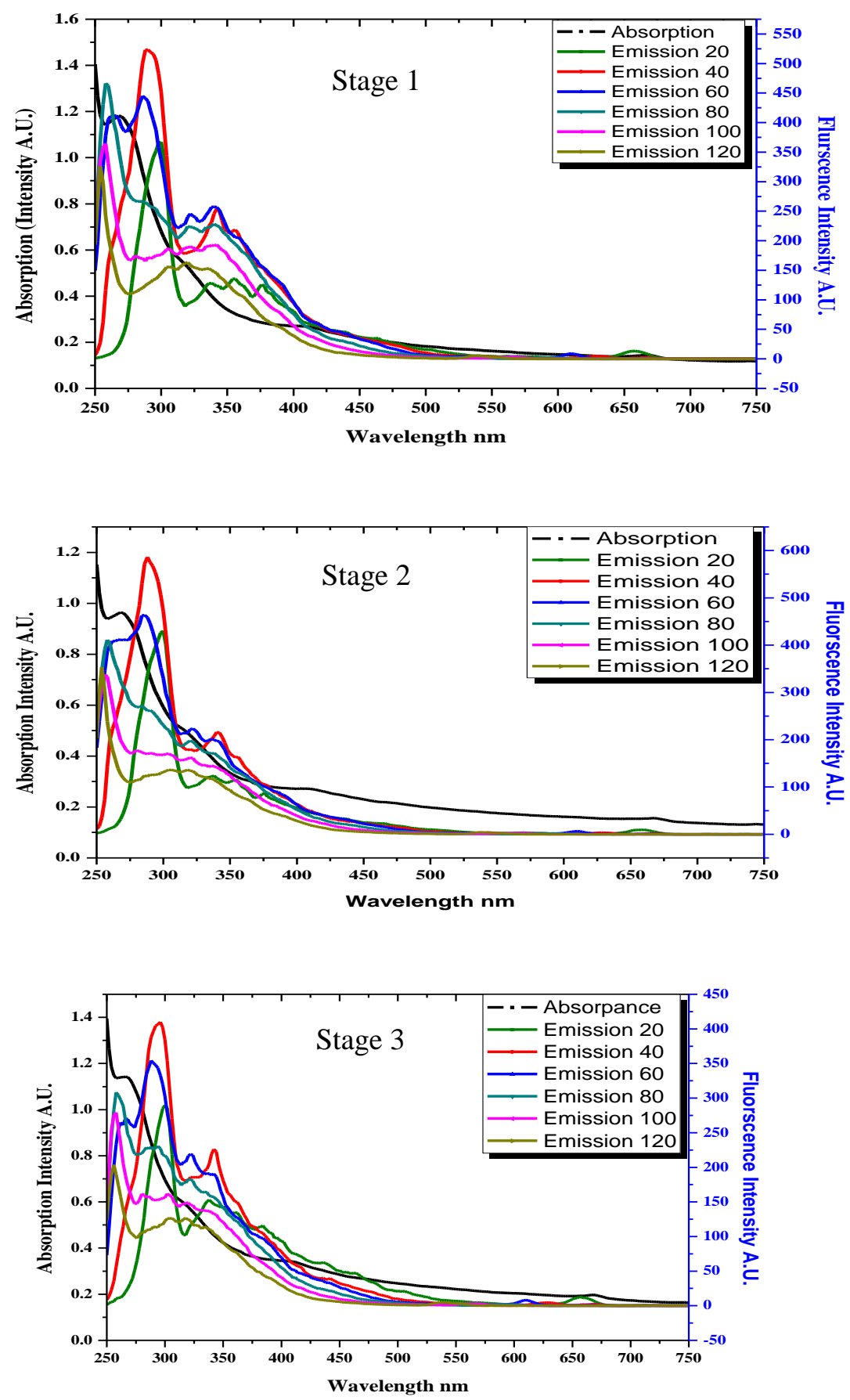

Fig. 3: Fluorescence and absorption intensities of olive oil of maturity stages at different interval wavelengths. 

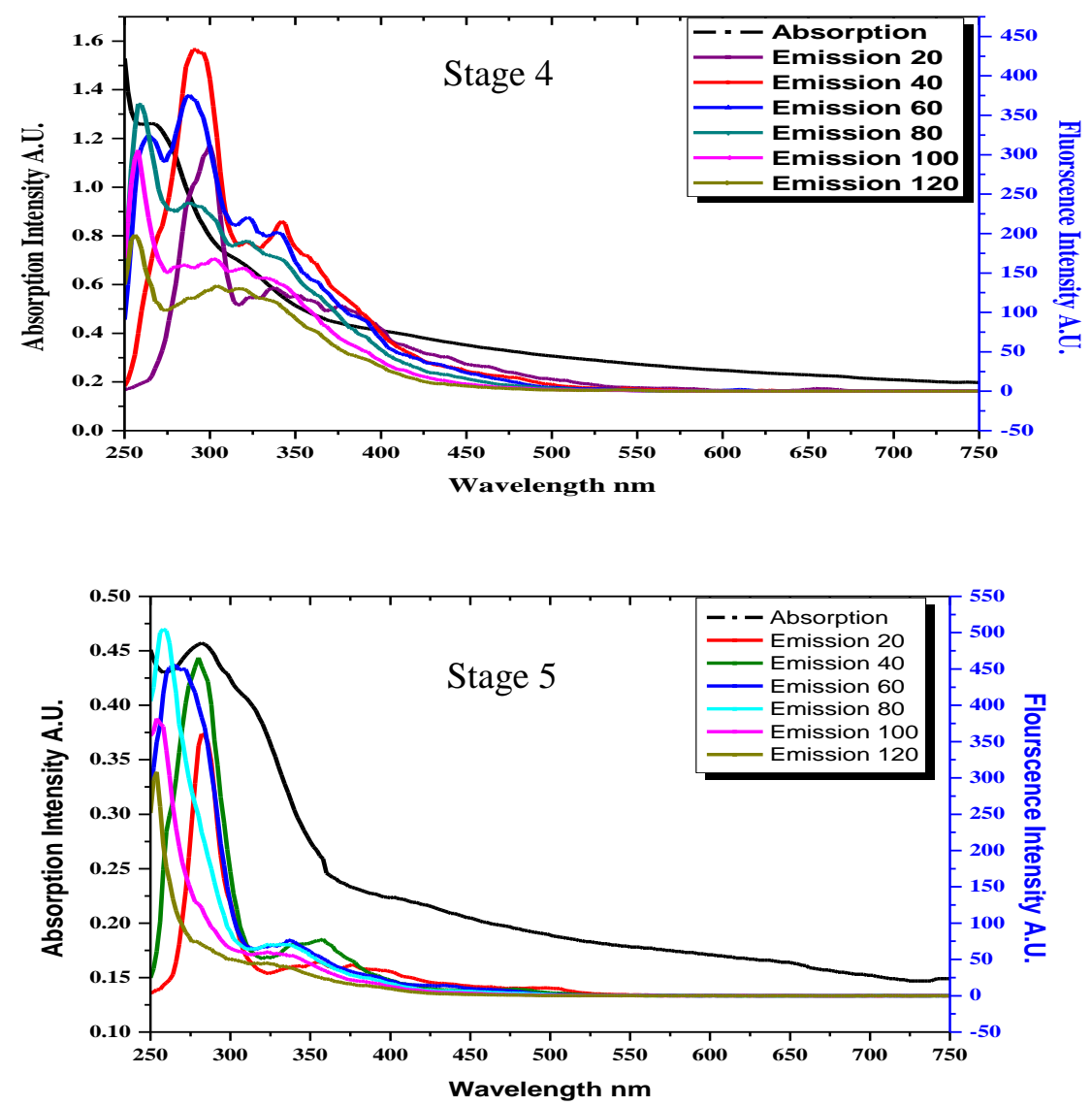

Cont. Fig. 3: Fluorescence and absorption intensities of olive oil of maturity stages at different interval wavelengths.

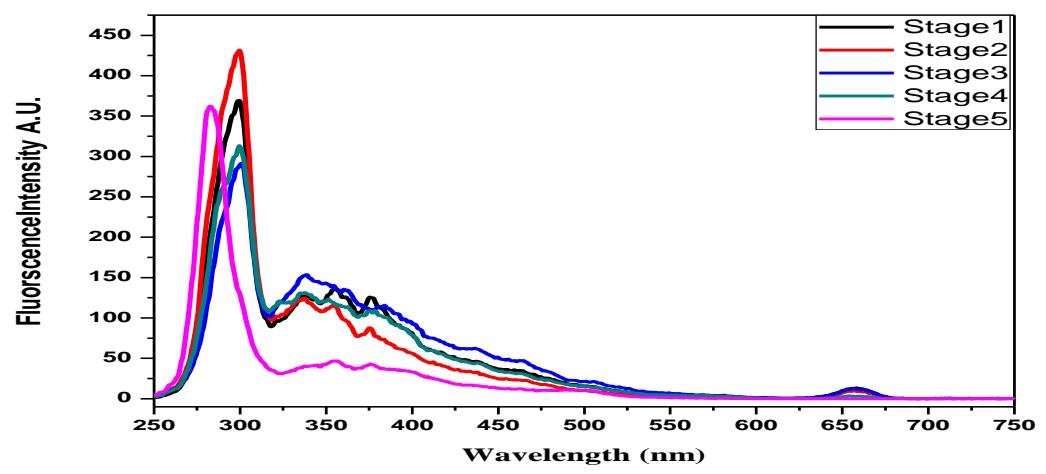

Fig. 4: Standard synchronous scan used for olive oil stages at $\Delta \lambda=20 \mathrm{~nm}$. 
The peaks of fluorescence intensity at $\Delta \lambda=100 \mathrm{~nm}$ were (364.32 a. u.), (337.94 and 162.17a. u.),( 279.23a. u.), (305.74, 168.22 and 156.80a. u.) and (381.72a. u.) for excitation wave lengths of (258nm), (256 and 320 $\mathrm{nm}),(258 \mathrm{~nm}),(258,302$ and $320 \mathrm{~nm})$ and $(254 \mathrm{~nm})$ for stages $1,2,3,4$ and 5 , respectively. The peaks of fluorescence intensity at $\Delta \lambda=120 \mathrm{~nm}$ were $326.05,353.26,203.73,133.79$ and 308.3 a. u. for excitation wave lengths of 254, 254, 256, 304 and $254 \mathrm{~nm}$ for stages $1,2,3,4$ and 5, respectively.

Fig. 5 shows the olive oil quality during olive maturity using interval wavelengths $(\Delta \lambda) 20,40,60,80,100$ and $120 \mathrm{~nm}$ to detect olic acid. it was found that the high peak of fluorescence intensity after interval wavelength when $\Delta \lambda=40 \mathrm{~nm}$ at using excitation wave length $405 \mathrm{~nm}$.

To detect palmtic acid, it was found the high peak of fluorescence intensity after interval wavelength when $\Delta \lambda=60 \mathrm{~nm}$ at using excitation wave length $273 \mathrm{~nm}$. To detect linolic acid at $325 \mathrm{~nm}$ according to Poulli et al., 2005. It was found that the high peak of fluorescence intensity after interval wavelength when $\Delta \lambda=60 \mathrm{~nm}$ at using excitation wave length $325 \mathrm{~nm}$.

To detect $\alpha$-tocopherol, it was found that the high peak of fluorescence intensity after interval wavelength when $\Delta \lambda=60 \mathrm{~nm}$ at using excitation wave length $301 \mathrm{~nm}$. To detect chlorophyll at $660 \mathrm{~nm}$, it was found that the high peak of fluorescence intensity after interval wavelength when $\Delta \lambda=20 \mathrm{~nm}$ at using excitation wave length $660 \mathrm{~nm}$., according to Sikorska et al., 2005.

It is clearly indicated that differentiation of virgin olive oil from low quality oils can be achieved using this wavelength region. This differences during maturity stages for olive oil can use for classification of oil, such spectra may be used, for example, in qualitative analysis and quantitative evaluation of some fluorescent pigments may be of interest for analytical purposes.

\section{CONCLUSIONS}

- The lowest value of $\Delta \lambda=20 \mathrm{~nm}$, with effective bandwidth reduction is observed as compared to the emission band, with the synchronous spectrum consisting of a single narrow band with a maximum at $301 \mathrm{~nm}$. - At higher $\Delta \lambda$ values at 60 and $80 \mathrm{~nm}$, the maximum of the synchronous spectrum is shifted to the blue and broadened, with additional fluorescence intensity changes. That shifting is related to change of constant wavelength differences $(\Delta \lambda)$. 


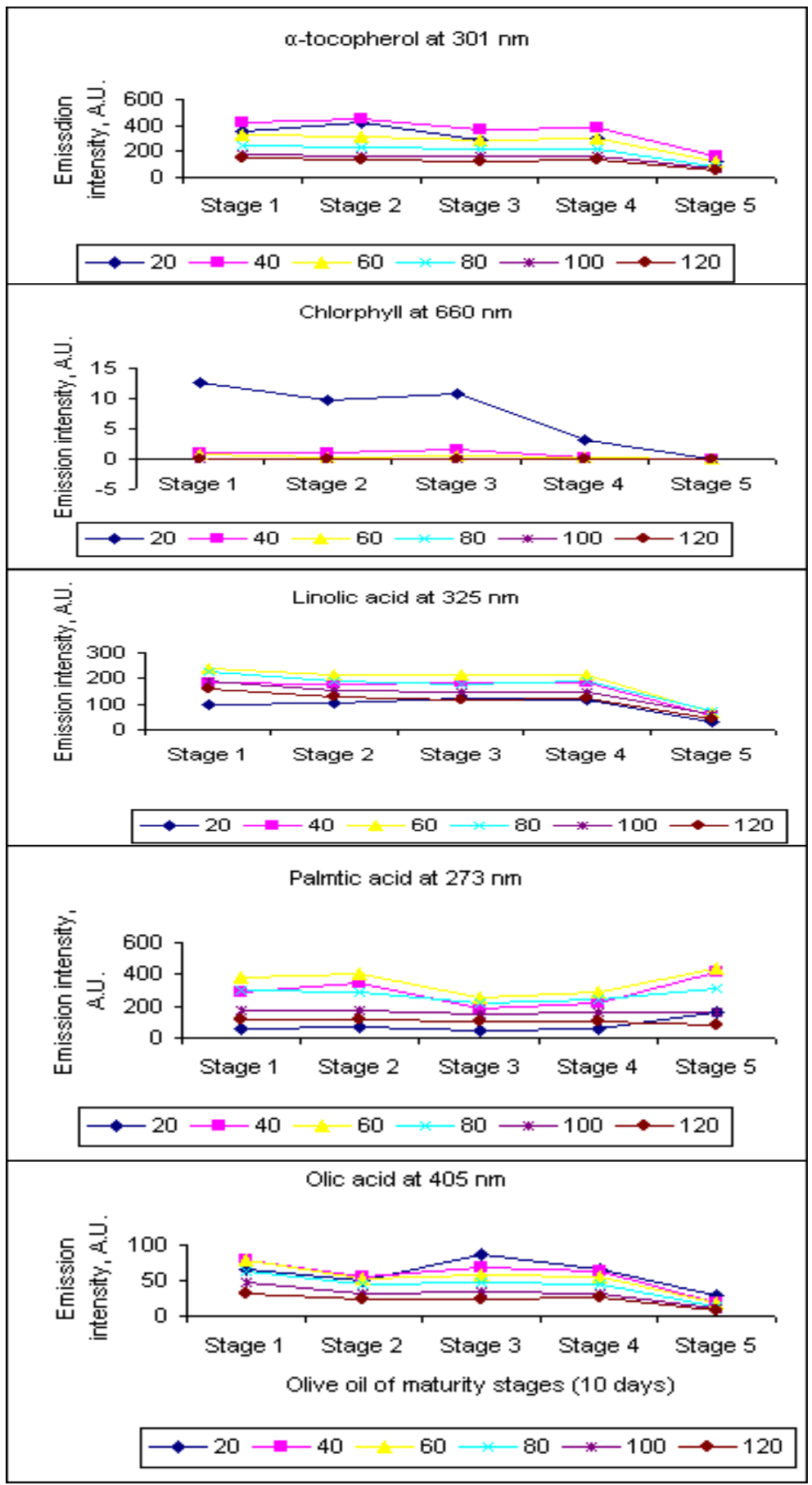

Fig. 5: Detection olive oil quality at different interval wavelengths. 
- It is clearly indicated that differentiation of olive oil from high quality oils can be achieved using different wavelength region at interval wavelengths $20,40,60,80,100$, and $120 \mathrm{~nm}$.

- The differences of fluorescence intensity during maturity stages for olive oil can be used for classification of oil according to its chemical component.

- Qualitative analysis evaluation of some fluorescent components may be of interest for identifying olive oil during olive maturity stages.

\section{REFERENCES}

Aguilera, M.P., Beltran, G., Ortega, D., Fernandez, A., Jimenez, A., Uceda, M. (2005). Characterization of virgin olive oil of Italian olive cultivars: Frantoio and Leccino, grown in Andalousia. Food Chem. 89:387-391.

Boskou, D., G. Blekas and M. Tsimidou (2005). Phenolic compounds in olive oil and olives. Current Topics in Nutraceutical Res., 3(2), 125-136.

DeMan, J. M. (1999). Principles of food chemistry. N. Y.: Kluwer Academic/Plenum Publisher., 3: 222-228.

Gomez-Alonso, S., M.D. Salvador and G. Fregapane (2002). Phenolic compounds profile of Cornicabra virgin olive oil. J. Agric. Food Chem. 50: 6812-6817.

Kiritsakis, A.K., Nauos, G.D., Polymenoupoulos, Z., Thomai, T., Sfakiotakis, E.Y., (1998). Effect of fruit storage conditions on olive oil quality. J. Am. Oil Chem. Soc. 75: 721-724.

Konstantina I. P., A. M. George and A. G. Constantinos (2007). Rapid synchronous fluorescence method for virgin olive oil adulteration assessment, Food Chem. 105 : 369-375

Kyriakidis, N. B., and P. Skarkalis (2000). Fluorescence spectra measurement of olive oil and other vegetable oils. J. of AOAC Int. 83(6): 1435-1439. 
Oldham P. B., M. E. McCarroll, L. B. McGown and I. M. Warner (2000). Molecular fluorescence, phosphorescence, and chemiluminescence spectrometry. Anal. Chem., 72:197R-209R.

Owen, R. W., A. Giacosa, W. E. Hull, R. Haubner, G. Wurtele, B. Spiegelhalder and H. Bartsch (2000). Olive oil consumption and health: The possible role of antioxidants. Lancet Oncology, 1: 107112.

Patre D. and A.K. Mishra (2002) Recent developments in multicomponent synchronous fluorescence scan analysis. Dep. of Chem., Indian Inst. of Tec., Madras,India. Trends in Anal. Chem. 21 (12): 1220-1225.

Poulli, K. I. ;G. A. Mousdis and C. A. Georgiou (2007) Rapid synchronous fluorescence method for virgin olive oil adulteration assessment. Chem. Lab., Ag. Un. of Athens, Greece Food Chem. 105:369-375.

Poulli, K. I., G. A. Mousdis and C. A. Georgiou (2005). Classification of edible and lampante virgin olive oil based on synchronous fluorescence and total luminescence spectroscopy. Anal. Chimica Acta, 542(2): 151-156.

Psomiadou, E., and M. Tsimidou (2001). Pigments in Greek virgin olive oils: occurrence ., 3(2), 125-136

Roca, M., and M. I. Minguez-Mosquera (2001c). Change in the natural ratio between chlorophylls and carotenoid in olive fruit during processing for virgin olive oil. J. of the Am. Oil Chem. Soc., 78: 133-138.

Sikorska E., G. Tomasz, V. K. Igor, S. Marek and K. Jacek (2005) Classification of edible oils using synchronous scanning fluorescence spectroscopy. Faculty of Commodity Sc., Pozna_n Un. of Ec., Poland. Food Chem. 89 : 217-225

Sikorska, E., A. Romaniuk, I. V. Khmelinskii, R. Herance, J. I. Bourdelande, M. Sikorski and J. Koziol (2003). Characterization of edible oils using total luminescence spectroscopy. J. of Fluor. 14: 25-35. 
Zandomeneghi, M., L. Carbonaro and C. Caffarata (2005). Fluorescence of vegetable oils: Olive oils. J. of Ag. and Food Chem. 53: 759-766.

\section{الملخص العربى}

\section{القلورة الضوئية لتقييم جودة الزيت خلال مراحل نضج الزيتون}

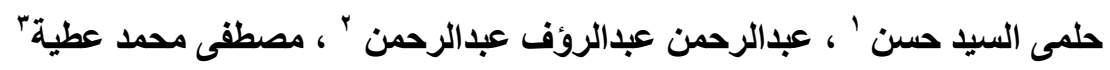

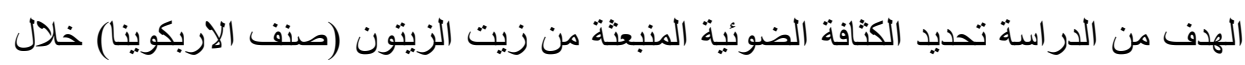

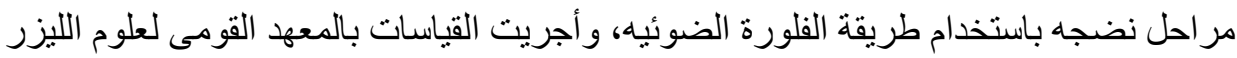

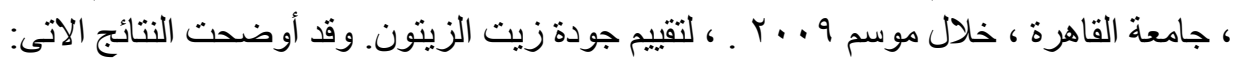

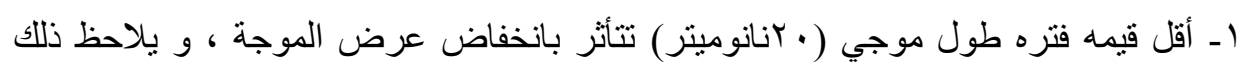
بمقارنة مدى الانبعاث مع مدى الطيف المنبعث.

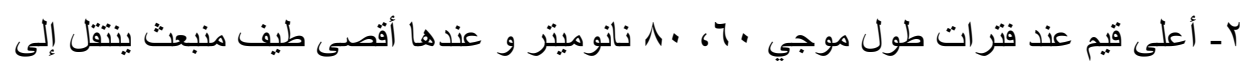
المنطقة الزرقاء بسبب تغير في الكثافة المنبعثة.

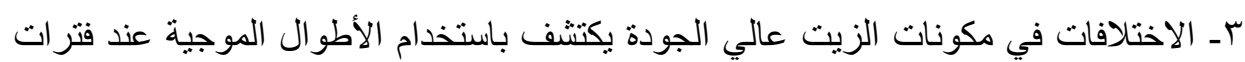

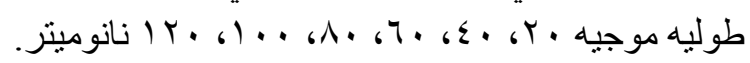

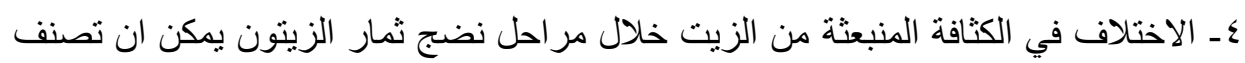
الزيت بناءا على التركيب الكيميائي. هـ تحليل الضوء المنبعث يمكن ان يميز مكونات زيت الزيتون (الكلورفيل و التيكوفلور

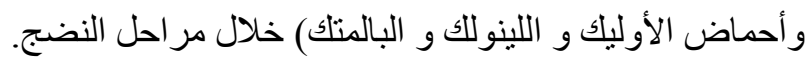

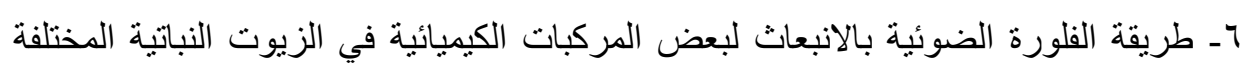

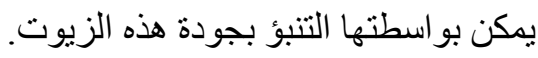

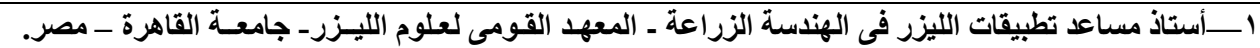

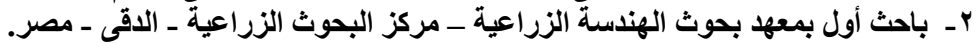

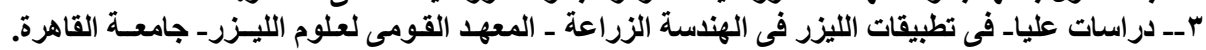

